\title{
Severe COPD cases from Korea, Poland, and USA have substantial differences in respiratory symptoms and other respiratory illnesses
}

This article was published in the following Dove Press journal: International Journal of COPD

\begin{abstract}
Woo Jin Kim,' Jae-Joon Yim, ${ }^{2}$ Deog Kyeom Kim, ${ }^{3}$ Myung Goo Lee, ${ }^{4}$ Anne L Fuhlbrigge, ${ }^{5}$ Pawel Sliwinski, ${ }^{6}$ Iwona Hawrylkiewicz, ${ }^{6}$ Emily S Wan, ${ }^{7,8}$ Michael H Cho, ${ }^{7,8}$ Edwin K Silverman ${ }^{7,8}$

'Department of Internal Medicine and Environmental Health Center, Kangwon National University Hospital, Chuncheon, ${ }^{2}$ Department of Internal Medicine, Division of Pulmonary and Critical Care Medicine, Seoul National University College of Medicine, Seoul, ${ }^{3}$ Department of Internal Medicine, Division of Pulmonary and Critical Care Medicine, Seoul Metropolitan Government-Seoul National University Boramae Medical Center, Seoul National University College of Medicine, Seoul, ${ }^{4}$ Division of Pulmonary, Allergy and Critical Care Medicine, Hallym University Chuncheon Sacred Heart Hospital, Chuncheon, Korea; ${ }^{5}$ Division of Pulmonary Sciences and Critical Care Medicine, University of Colorado School of Medicine, Aurora, CO, USA; ${ }^{6} 2$ nd Department of Respiratory Medicine, Institute of Tuberculosis and Lung Diseases, Warsaw, Poland; ${ }^{7}$ Channing Division of Network Medicine, ${ }^{8}$ Division of Pulmonary and Critical Care Medicine, Brigham and Women's Hospital, Boston, MA, USA
\end{abstract}

Correspondence: Edwin K Silverman Channing Division of Network Medicine, Brigham and Women's Hospital, I8I Longwood Avenue, Boston, MA 02115, USA Email ed.silverman@channing.harvard.edu

Woo Jin Kim

Department of Internal Medicine and Environmental Health Center, Kangwon National University Hospital, School of

Medicine, Kangwon National University, I56 Beakryeong-ro, Chuncheon, Gangwon-do 24289, 19300 South Korea

Email pulmo2@kangwon.ac.kr
Purpose: Chronic obstructive pulmonary disease (COPD), characterized by irreversible airflow obstruction, is a major cause of morbidity and mortality worldwide. However, geographic differences in the clinical characteristics of severe COPD patients have not been widely studied. Methods: We recruited a total of 828 severe COPD cases from three continents. Subjects in Poland were enrolled by the Institute of Tuberculosis and Lung Diseases in Warsaw; subjects in Korea participated at several university hospitals in Korea; and subjects in USA were enrolled at two clinics affiliated with academic medical centers. All subjects were over the age of 30 with at least 10 pack-years of cigarette smoking history. Cases manifested severe to very severe airflow obstruction with post-bronchodilator forced expiratory volume in 1 second $\left(\mathrm{FEV}_{1}\right)<50 \%$ predicted and $\mathrm{FEV}_{1} /$ forced vital capacity $<0.7$. All subjects completed a detailed questionnaire and underwent standardized pre-bronchodilator and post-bronchodilator spirometry. Subjects with known tuberculosis (TB)-associated lung parenchymal destruction were excluded. Univariate and multivariate assessments of the impact of the country of origin on respiratory symptoms and respiratory illness were performed.

Results: In both univariate and multivariate analyses, a history of TB (38.7\%) and physiciandiagnosed asthma (43.9\%) were significantly more common in subjects with severe COPD from Korea than USA or Poland, while attacks of bronchitis (64.2\%) were more common in subjects with severe COPD from Poland. COPD subjects from Poland had more severe dyspnea (modified Medical Research Council 3.3 \pm 1.0 ) and more frequently reported symptoms of chronic bronchitis (52.2\%). A history of TB was also more common in Poland (10.8\%) than in USA $(0.3 \%)$ severe COPD patients.

Conclusion: Respiratory symptoms and other respiratory illnesses associated with severe COPD differed widely among three continents.

Keywords: COPD, epidemiology, respiratory symptoms, tuberculosis

\section{Introduction}

Chronic obstructive pulmonary disease (COPD), which is characterized by irreversible airflow obstruction, is a major cause of morbidity and mortality worldwide. ${ }^{1}$ Cigarette smoking is the most important known risk factor for the development of COPD. However, the susceptibility toward developing airflow obstruction and the specific clinical phenotypes manifested are markedly variable. Occupational exposures and air pollution are also known to contribute to the risk of COPD and may contribute to the development of COPD among nonsmokers. ${ }^{2}$

There are known ethnic differences in respiratory diseases including COPD. ${ }^{3}$ Geographic differences in severe COPD have not been widely studied, however. 
The BOLD study assessed airflow obstruction prevalence in different countries and found substantial differences between countries in the prevalence of COPD, ${ }^{4}$ although most of the COPD cases had mild or moderate disease. A recent international patient survey showed substantial variations in respiratory symptoms and health status. ${ }^{5}$ Ethnic differences, filterless cigarette use, air pollution, and other environmental exposures may affect COPD-related phenotypes including airflow obstruction severity, respiratory symptoms, and comorbidities. However, only a small percentage of severe COPD subjects, who have the greatest increased risk of COPD mortality and morbidity, has been included in such international studies.

We enrolled severe COPD subjects and smoker controls in Korea and Poland in the Transcontinental COPD Genetics Study (TCGS) and severe COPD cases in a study of frequent and infrequent exacerbators from the USA. These subjects were studied with the same core set of questionnaire items and the same spirometry protocol. The participants offer a unique opportunity to compare differences of COPD-related risk factors and respiratory symptoms in these different countries. We hypothesized that severe COPD subjects in different geographic regions would have differences in respiratory symptoms, environmental exposures, and other respiratory illnesses.

\section{Methods}

\section{Study populations}

We included study subjects from the TCGS (Poland and Korea) and the COPD Exacerbations Study (USA).

TCGS subjects in Poland were enrolled by the Institute of Tuberculosis and Lung Diseases (Warsaw, Poland), ${ }^{6}$ and subjects in Korea participated at four university hospitals in Korea. All TCGS subjects were over the age of 40 with at least 10 pack-years of cigarette smoking history. Cases had severe to very severe airflow obstruction with post-bronchodilator forced expiratory volume in 1 second $\left(\mathrm{FEV}_{1}\right)<50 \%$ predicted and $\mathrm{FEV}_{1} /$ forced vital capacity $(\mathrm{FVC})<0.7$. Control subjects demonstrated normal lung function (post-bronchodilator $\mathrm{FEV}_{1} \geq 80 \%$ predicted and $\mathrm{FEV}_{1} / \mathrm{FVC} \geq 0.7$ ). Subjects were excluded because of concomitant respiratory disorders such as diffuse bronchiectasis and interstitial lung disease affecting pulmonary function (except for asthma), lung surgery, pregnancy, and respiratory infections in the month before enrollment. We also excluded subjects with known tuberculosis (TB)associated lung parenchymal destruction that may have contributed to airflow limitation based on the involvement of more than one lobe of a lung.
COPD Exacerbations Study subjects were enrolled at Fallon Clinic and Harvard Vanguard Medical Associates in Massachusetts, as previously reported. ${ }^{7}$ Subjects were over 30 years of age with at least 10 pack-years of smoking, and severe COPD subjects met the same spirometric criteria as TCGS COPD cases. Frequent exacerbators had an average of two COPD exacerbations per year while non-exacerbators had no exacerbations in the prior 12 months. Subjects with chronic lung disorders such as lung cancer, TB, pulmonary fibrosis, or asbestosis were excluded.

Subjects underwent standardized pre-bronchodilator and post-bronchodilator spirometry, using the EasyOne Spirometer (ndd, Inc, Andover, MA, USA), in accordance with American Thoracic Society/European Respiratory Society criteria. ${ }^{8}$ Post-bronchodilator spirometry was performed $\sim 20$ minutes after administration of $180 \mu \mathrm{g}$ of albuterol via a metered dose inhaler. Subjects completed a modified American Thoracic Society Respiratory Epidemiology questionnaire. ${ }^{9,10}$ Questionnaires in Polish and Korean were back-translated to English to confirm translation accuracy. Respiratory symptoms and illnesses were assessed by the same questions in all three countries. Usual cough was assessed by the question "Do you usually have a cough?" Usual phlegm was assessed by the question "Do you usually bring up phlegm from your chest?" Wheezing was assessed by the question "Does your chest ever sound wheezy or whistling?" Attacks of wheezing were assessed by the question "Have you ever had an attack of wheezing that has made you feel short of breath?" Chronic bronchitis was defined as both cough and phlegm for at least 3 months per year for at least the last 2 years. All subjects provided written informed consent, and this study was approved by the institutional review boards at each participating institution (Partners Human Research Committee for the Exacerbations Study [2006P000295], Korean Study [2005P001370], and Polish Study [2004P001795]; Institute of Tuberculosis and Lung Diseases [Warsaw, Poland]; Seoul National University [Seoul, South Korea]; Seoul National University Boramae Hospital [Seoul, South Korea]; Kangwon National University Hospital [Chuncheon, South Korea]; and Saint Vincent Hospital/Fallon Community Health Plan Institutional Review Board [Worcester, MA, USA]).

\section{Statistical analysis}

Univariate analyses were performed using chi-square tests for $3 \times 2$ contingency tables of categorical variables except for contingency tables with cells containing $<5$ expected observations, in which Fisher's exact tests were used. Student's $t$-tests and analysis of variance with Student-Newman-Keuls 
tests were used for univariate analysis of continuous variables. Differences in respiratory symptoms and other respiratory illnesses between different countries were assessed using multivariable logistic regression with the country of origin as the dependent variable, while adjusting for sex, age, pack-years of cigarette smoking, and $\mathrm{FEV}_{1}$ (\% predicted). All analyses were performed using SAS (version 9.4; SAS Institute Inc, Cary, NC, USA).

\section{Results}

From the TCGS, 316 Polish subjects and 173 Korean subjects with severe COPD were included. From the USA, 339 severe COPD subjects from the COPD Exacerbations Study were included (Table 1). Controls for the TCGS included 322 Polish and 256 Korean smokers with normal spirometry.

\section{Comparison of demographic, spirometric, and clinical characteristics of severe COPD cases}

Severe COPD subjects from Korea were almost entirely male, while Polish cases tended to be younger (Table 1). Body mass index was lower in Korean subjects, and lung function levels were slightly more severely reduced among cases enrolled in Poland.

In univariate analyses of respiratory symptoms (Table 2 and Figure 1), COPD subjects from Poland had higher rates of usual cough, usual phlegm, and chronic bronchitis defined by cough/phlegm in $\geq 3$ months a year for $\geq 2$ years as well as greater dyspnea (modified Medical Research Council scale) than patients in Korea and USA. Korean subjects reported decreased prevalence of ever wheezing but more frequent attacks of wheezing. Respiratory illnesses and environmental

Table I Demographic and spirometric characteristics of severe COPD subjects from three countries ( $\mathrm{N}[\%]$ or mean \pm standard deviation)

\begin{tabular}{|c|c|c|c|c|}
\hline & $\begin{array}{l}\text { Poland } \\
(n=3 \mid 6)\end{array}$ & $\begin{array}{l}\text { Korea } \\
(n=\mid 73)\end{array}$ & $\begin{array}{l}\text { USA } \\
(n=339)\end{array}$ & $\begin{array}{l}p \text {-value for } \\
\text { differences } \\
\text { between } 3 \\
\text { COPD } \\
\text { groups }\end{array}$ \\
\hline Gender, male & $221(69.9)$ & $172(99.4)$ & $158(46.6)$ & $<0.0001$ \\
\hline Age & $62.4 \pm 7.4^{\mathrm{k}, \mathrm{u}}$ & $68.9 \pm 6.2^{\mathrm{p}}$ & $68.5 \pm 8.3^{p}$ & $<0.0001$ \\
\hline BMI & $26.8 \pm 5.9^{\mathrm{k}, u}$ & $21.2 \pm 3.1^{\mathrm{u}, \mathrm{p}}$ & $28.5 \pm 6.7^{\mathrm{k}, \mathrm{p}}$ & $<0.0001$ \\
\hline Post-bronchodilator & $0.88 \pm 0.32^{k}$ & $0.94 \pm 0.27^{p}$ & $0.89 \pm 0.28$ & 0.06 \\
\hline $\begin{array}{l}\text { FEV } \\
\text { Post-bronchodilator } \\
\text { FEV }(\%)\end{array}$ & $30.2 \pm 9.4^{\mathrm{k}, \mathrm{u}}$ & $I^{P}$ & $\pm 8.7^{\mathrm{P}}$ & I \\
\hline
\end{tabular}

Note: For continuous variables, ${ }^{k}$ corresponds to significant difference with Korea, "corresponds to significant difference with USA, and Pcorresponds to significant difference with Poland.

Abbreviations: COPD, chronic obstructive pulmonary disease; BMI, body mass index; $\mathrm{FEV}_{1}$, forced expiratory volume in I second. exposures also differed between groups. Korean COPD patients had higher rates of history of self-reported TB and history of physician-diagnosed asthma, but lower rates of pneumonia, attacks of bronchitis, and lung trouble before the age of 16 (Table 2). USA COPD patients had higher cumulative smoke exposure (pack-years) and earlier age of smoking onset. COPD cases in Poland and USA reported more frequent occupational exposures to gases or chemical fumes than in Korea. Similar relationships were observed in analyses limited to male COPD subjects only (Table S1).

\section{Subgroup analysis in COPD cases with FEV,$<30 \%$ predicted}

In order to determine whether differences in respiratory symptoms, other respiratory illnesses, and environmental exposures were consistent for both severe and very severe COPD subjects, stratified comparisons were made for COPD subjects with $\mathrm{FEV}_{1}<30 \%$ predicted and $\mathrm{FEV}_{1}$ values equaling $30 \%-50 \%$ predicted (Table 3 ). Compared to analyses in the full set of COPD cases, similar trends in univariate analyses were observed across both severity strata for respiratory symptoms, with more cough/phlegm and dyspnea symptoms in Poland; differences in the prevalence of attacks of wheezing were not significant. Higher rates of TB and physician-diagnosed asthma and lower rates of pneumonia were observed in both strata among Koreans. Differences between populations for occupational gas/fume exposure were not significant among very severe COPD cases.

\section{Comparison of respiratory illnesses and environmental exposures in COPD cases and controls in Korea and Poland}

To determine if the observed differences between severe COPD cases between countries could be related to population-level differences that would also be observed in smokers without airflow obstruction, we compared COPD cases and controls in Poland and Korea (Table 4). In both countries, the rates of TB, pneumonia, lung trouble before the age of 16, and attacks of bronchitis were significantly higher in COPD cases than controls. Cumulative smoke exposure (pack-years) was higher among COPD cases in both countries, while occupational gas/fume exposure was only higher among COPD cases compared to controls in Poland.

\section{Multivariable analysis for country-specific effects of respiratory symptoms and respiratory illnesses}

Multivariable analysis was performed with adjustment for age, sex, pack-years of smoking, and $\mathrm{FEV}_{1} \%$ predicted 
Table 2 Respiratory symptoms, respiratory illnesses, and environmental exposures in severe COPD subjects according to country ( $\mathrm{N}[\%]$ or mean \pm standard deviation)

\begin{tabular}{|c|c|c|c|c|}
\hline & $\begin{array}{l}\text { Poland } \\
(n=3 \mid 6)\end{array}$ & $\begin{array}{l}\text { Korea } \\
(n=173)\end{array}$ & $\begin{array}{l}\text { USA } \\
(n=339)\end{array}$ & $p$-value \\
\hline \multicolumn{5}{|l|}{ Respiratory symptoms } \\
\hline Usual cough & $239(75.6)$ & $76(43.9)$ & $153(45.1)$ & $<0.0001$ \\
\hline Usual phlegm & $250(79.1)$ & $106(61.3)$ & I8I (53.4) & $<0.000$ I \\
\hline Chronic bronchitis & $165(52.2)$ & $48(27.8)$ & $127(37.5)$ & $<0.0001$ \\
\hline Wheezing & $254(80.4)$ & $116(67.1)$ & $28 I(82.9)$ & 0.0001 \\
\hline Attacks of wheezing & $137(43.4)$ & $96(55.5)$ & I $55(45.7)$ & 0.03 \\
\hline mMRC dyspnea* & $3.3 \pm 1.0$ & $2.5 \pm 1.2$ & $2.8 \pm 1.2$ & $<0.000$ I \\
\hline \multicolumn{5}{|l|}{ Respiratory illnesses } \\
\hline History of pneumonia & $184(58.2)$ & $38(22.0)$ & $228(67.3)$ & $<0.000$ I \\
\hline History of tuberculosis & $34(10.8)$ & $67(38.7)$ & I (0.3) & $<0.0001$ \\
\hline Attacks of bronchitis & $203(64.2)$ & $8(4.6)$ & $201(59.3)$ & $<0.0001$ \\
\hline Physician-diagnosed asthma & $5(1.6)$ & $76(43.9)$ & $108(31.9)$ & $<0.0001$ \\
\hline Lung trouble before age 16 & $49(15.5)$ & II (6.4) & $45(13.3)$ & 0.01 \\
\hline \multicolumn{5}{|l|}{ Environmental exposures } \\
\hline Pack-years of smoking & $44.4 \pm 22.5$ & $45.0 \pm 23.5$ & $62.1 \pm 34.2$ & $<0.0001$ \\
\hline Current smoking & $80(25.3)$ & $43(24.9)$ & $74(21.9)$ & 0.6 \\
\hline Age when started smoking & I8.6 (3.8) & $20.9(5.5)$ & $16.6(4.9)$ & $<0.0001$ \\
\hline Childhood household smoke exposure & $268(84.8)$ & I 34 (77.5) & $278(82.5)$ & 0.12 \\
\hline Occupational dust exposure & $197(62.7)$ & $84(53.9)$ & $182(54.3)$ & 0.06 \\
\hline Occupational gas/chemical fume exposure & $135(43.0)$ & $20(12.8)$ & I4I (42.I) & $<0.0001$ \\
\hline
\end{tabular}

Note: $*_{n}=304$ (Poland), n=152 (Korea), n=264 (USA) for mMRC dyspnea analysis.

Abbreviations: mMRC, modified Medical Research Council; COPD, chronic obstructive pulmonary disease.

to determine which respiratory symptoms among severe COPD cases were significantly and independently associated with the country of origin. As shown in Table 5, increased prevalence of chronic bronchitis, decreased prevalence of attacks of wheezing, and increased dyspnea were associated with Polish COPD cases relative to both Korea and USA. Increased prevalence of chronic bronchitis was noted in COPD cases in USA relative to Korean COPD cases.

Similar multivariable analyses were performed with other respiratory illnesses (Table 6). As in the univariate analyses, a history of TB and physician-diagnosed asthma were most strongly associated with Korean COPD cases

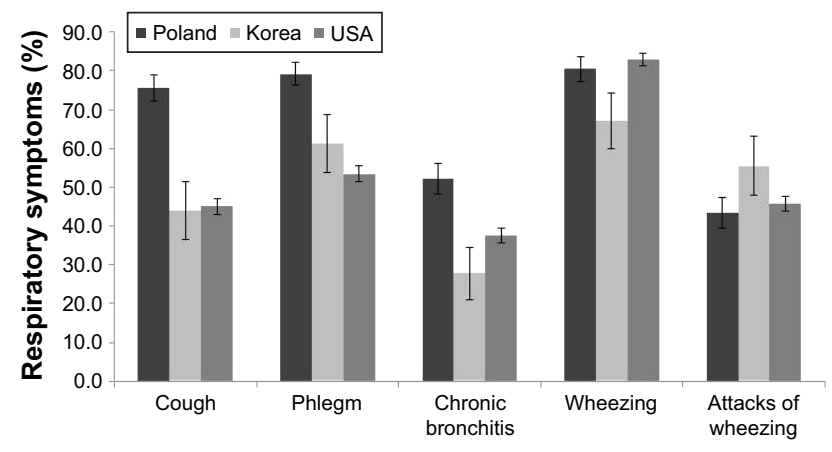

Figure I Comparison of respiratory symptoms between severe COPD cases in Poland, Korea, and USA. relative to USA and Poland. TB was associated with Polish rather than USA COPD cases, while asthma was associated with USA rather than Polish COPD cases. A history of pneumonia was less strongly associated with the Korean COPD cases relative to Poland and USA, while attacks of bronchitis were most strongly associated with Poland.

\section{Discussion}

In the current study, we compared clinical characteristics of severe COPD subjects whose post-bronchodilator $\mathrm{FEV}_{1}$ values were $<50 \%$ of predicted from Korea, Poland, and USA. Prevalence of respiratory symptoms and other respiratory illnesses, as well as demographic and smoking exposures, differed substantially across severe COPD cases from these three countries. TB and asthma were more common in severe COPD cases from Korea. In Korea, severe COPD was observed almost exclusively in men; this is likely due to the historically higher rates of smoking among men than women in Korea. Chronic bronchitis and dyspnea were more prominent among Polish COPD cases, while wheezing was less frequently reported. Polish COPD cases reported high rates of previous pneumonia and attacks of bronchitis; they reported an elevated rate of TB compared to USA. COPD patients in USA had high rates of attacks of bronchitis and 
Table 3 Stratified comparison of respiratory symptoms, respiratory illnesses, and environmental exposures between countries in GOLD spirometry grade 3 (severe COPD) versus 4 (very severe COPD) ( $N$ [\%] or mean \pm standard deviation)

\begin{tabular}{|c|c|c|c|c|c|c|c|c|}
\hline & \multicolumn{4}{|c|}{$\mathbf{F E V}_{\mathbf{1}} \%<\mathbf{3 0}$} & \multicolumn{4}{|c|}{ FEV $_{1} \% \geq \mathbf{3 0}$} \\
\hline & $\begin{array}{l}\text { Poland } \\
(n=161)\end{array}$ & $\begin{array}{l}\text { Korea } \\
(n=46)\end{array}$ & $\begin{array}{l}\text { USA } \\
(n=106)\end{array}$ & $p$-value & $\begin{array}{l}\text { Poland } \\
(n=\mid 55)\end{array}$ & $\begin{array}{l}\text { Korea } \\
(n=\mid 27)\end{array}$ & $\begin{array}{l}\text { USA } \\
(n=233)\end{array}$ & $p$-value \\
\hline Usual cough & $123(76.4)$ & $17(37.0)$ & $50(47.2)$ & $<0.0001$ & $116(74.8)$ & $59(46.5)$ & $103(44.2)$ & $<0.0001$ \\
\hline Usual phlegm & I $33(82.6)$ & $29(63.0)$ & $58(54.7)$ & $<0.0001$ & $117(75.5)$ & $77(60.6)$ & $123(52.8)$ & $<0.000 \mathrm{I}$ \\
\hline Chronic bronchitis & $86(53.4)$ & II (23.9) & $4 \mathrm{I}(38.7)$ & 0.0007 & $79(51.0)$ & $37(29.1)$ & $86(36.9)$ & 0.0006 \\
\hline Wheezing & $128(79.5)$ & $31(67.4)$ & $89(84.0)$ & 0.07 & $126(81.3)$ & $85(66.9)$ & $192(82.4)$ & 0.002 \\
\hline Attacks of wheezing & $70(43.5)$ & $25(54.4)$ & $4 I(38.7)$ & 0.2 & $67(43.2)$ & 71 (55.9) & II 4 (48.9) & 0.1 \\
\hline mMRC dyspnea* & $3.53 \pm 0.82$ & $3.14 \pm 0.95$ & $3.08 \pm 1.03$ & 0.0005 & $3.03 \pm 1.07$ & $2.23 \pm 1.22$ & $2.61 \pm 1.23$ & $<0.000$ I \\
\hline Pneumonia & $98(60.9)$ & II (23.9) & $6 \mathrm{I}(57.6)$ & $<0.0001$ & $86(55.5)$ & $27(2 \mid .3)$ & 167 (7I.7) & $<0.0001$ \\
\hline Tuberculosis & $14(8.7)$ & $22(47.8)$ & $0(0.0)$ & $<0.000$ I & $20(12.9)$ & $45(35.4)$ & $\mathrm{I}(0.4)$ & $<0.000$ I \\
\hline Attacks of bronchitis & $112(69.6)$ & $4(8.7)$ & $66(62.3)$ & $<0.000 \mathrm{I}$ & 91 (58.7) & $4(3.2)$ & 135 (57.9) & $<0.000$ I \\
\hline Physician-diagnosed asthma & $2(1.2)$ & $22(47.8)$ & $25(23.6)$ & $<0.0001$ & $3(1.9)$ & $54(42.5)$ & $83(35.6)$ & $<0.000$ I \\
\hline Lung trouble before age 16 & $27(16.8)$ & $3(6.5)$ & $13(12.3)$ & 0.2 & $22(14.2)$ & $8(6.3)$ & $32(13.7)$ & 0.07 \\
\hline Pack-years & $45.8 \pm 22.3$ & $40.0 \pm 13.7$ & $65.4 \pm 37.9$ & $<0.000 \mathrm{I}$ & $43.1 \pm 22.7$ & $46.9 \pm 26.0$ & $60.6 \pm 32.3$ & $<0.0001$ \\
\hline Age when started smoking & $18.6 \pm 3.6$ & $21.1 \pm 3.4$ & $16.4 \pm 4.9$ & $<0.000$ I & $18.7 \pm 3.9$ & $20.9 \pm 6.1$ & $16.7 \pm 4.9$ & $<0.000$ I \\
\hline Occupational gas/fume exposure & $67(42.1)$ & $12(28.6)$ & $46(43.8)$ & 0.2 & 68 (43.9) & $8(7.0)$ & $95(4 \mid .3)$ & $<0.0001$ \\
\hline
\end{tabular}

Notes: *For mMRC dyspnea analysis, $n=42$ (Korea) and $n=88$ (USA) in very severe (FEV $<30 \%$ ) analyses; and $n=110$ (Korea) and $n=176$ (USA) in severe (FEV $\geq 30 \%$ ) analyses. Abbreviations: mMRC, modified Medical Research Council; COPD, chronic obstructive pulmonary disease; GOLD, Global initiative for chronic Obstructive Lung Disease; $\mathrm{FEV}_{1}$, forced expiratory volume in I second.

pneumonia. Thus, our results revealed that patients with severe COPD showed important differences in clinical features associated with COPD and varying histories of respiratory illness and exposures between these three countries.

In terms of past respiratory infections, rates of a previous history of TB were highest in Korea. History of TB treatment has been previously reported to be an important risk factor for COPD ${ }^{11,12}$ with a high prevalence of airflow obstruction after treatment of active TB. ${ }^{13}$ Prevalence of TB in Asian countries is higher than that in Western countries. ${ }^{14}$ Compared to other countries, South Korea is known to have a surprisingly high prevalence of TB given its level of economic development. ${ }^{15}$ We excluded subjects whose airflow limitation was known to be related to parenchymal lung destruction from TB; however, undiagnosed bronchiectasis or other lung parenchymal damage from TB may have contributed to the characteristics of severe COPD subjects in Korea. Although a history of infection with TB may be an important risk factor for COPD, the impact of previous TB on the development and degree of airflow limitation has not been reported. Studies examining how regional differences in TB may affect the severity of airflow limitation in COPD are warranted. We suspect that the differential impact of TB on COPD risk in Korea, Poland, and USA is related to differences in TB prevalence in these countries. However, the significant differences in TB rates between COPD cases and smoking controls in both Korea and Poland (Table 4) suggest that TB is a potentially important risk factor for COPD in those countries.

Table 4 Comparison of respiratory illnesses and environmental exposures in severe COPD cases and controls from Poland and Korea ( $\mathrm{N}[\%]$ or mean \pm standard deviation)

\begin{tabular}{|c|c|c|c|c|c|c|}
\hline & \multicolumn{3}{|l|}{ Poland } & \multicolumn{3}{|l|}{ Korea } \\
\hline & $\begin{array}{l}\text { COPD } \\
(n=316)\end{array}$ & $\begin{array}{l}\text { Controls } \\
(n=322)\end{array}$ & $p$-value & $\begin{array}{l}\text { COPD } \\
(n=173)\end{array}$ & $\begin{array}{l}\text { Controls } \\
(n=256)\end{array}$ & $p$-value \\
\hline Pneumonia & $184(58.2)$ & $60(18.6)$ & $<0.000$ I & $38(22.0)$ & $3(1.2)$ & $<0.0001$ \\
\hline Tuberculosis & $34(10.8)$ & $5(1.6)$ & $<0.000$ I & $67(38.7)$ & $13(5.1)$ & $<0.0001$ \\
\hline Attacks of bronchitis & $203(64.2)$ & $82(25.5)$ & $<0.000$ I & $8(4.6)$ & I $(0.4)$ & 0.004 \\
\hline Physician-diagnosed asthma & $5(1.6)$ & $\mathrm{I}(0.3)$ & 0.1 & $76(43.9)$ & $3(1.2)$ & $<0.0001$ \\
\hline Lung trouble before age 16 & $49(15.5)$ & $22(6.8)$ & 0.0005 & II (6.4) & $4(1.6)$ & 0.008 \\
\hline Pack-years & $44.4 \pm 22.5$ & $33.8 \pm 15.2$ & $<0.000$ I & $45.0 \pm 23.5$ & $27.4 \pm 15.2$ & $<0.0001$ \\
\hline Age when started smoking & $18.6 \pm 3.8$ & $19.5 \pm 4.0$ & 0.006 & $20.9 \pm 5.5$ & $20.7 \pm 3.5$ & 0.6 \\
\hline Occupational gas/fume exposure & $135(43)$ & $77(24.3)$ & $<0.0001$ & $20(12.8)$ & $22(8.8)$ & 0.2 \\
\hline
\end{tabular}

Abbreviation: COPD, chronic obstructive pulmonary disease. 
Table 5 Multivariate models for respiratory symptoms among severe COPD cases in different countries

\begin{tabular}{|c|c|c|c|c|c|c|}
\hline \multirow{2}{*}{$\begin{array}{l}\text { Respiratory } \\
\text { symptoms }\end{array}$} & \multicolumn{2}{|l|}{ Korea vs Poland* } & \multicolumn{2}{|l|}{ USA vs Poland*** } & \multicolumn{2}{|l|}{ USA vs Korea** } \\
\hline & OR with $95 \% \mathrm{Cl}$ & $p$-value & OR with $95 \% \mathrm{Cl}$ & $p$-value & OR with $95 \% \mathrm{CI}$ & $p$-value \\
\hline Chronic bronchitis & $0.30(0.18-0.52)$ & $<0.0001$ & $0.59(0.39-0.90)$ & 0.01 & $1.83(1.05-3.17)$ & 0.03 \\
\hline mMRC dyspnea & $0.50(0.38-0.66)$ & $<0.0001$ & $0.55(0.44-0.68)$ & $<0.000 \mathrm{I}$ & $0.96(0.76-1.2 I)$ & 0.7 \\
\hline Attacks of wheezing & $2.56(1.48-4.42)$ & 0.0008 & $1.75(1.14-2.67)$ & 0.01 & $0.62(0.36-1.06)$ & 0.08 \\
\hline
\end{tabular}

Notes: *Korean COPD cases are considered the reference population (ie, OR < I denotes "decreased" prevalence in Korean cases). **USA COPD cases are considered the reference population (ie, OR <I denoted "decreased" prevalence in USA cases). Logistic regression models used country of origin as the dependent variable, with independent variables including all three respiratory symptoms as well as age, sex, pack-years of smoking, and post-bronchodilator FEV (\% predicted). mMRC dyspnea is expressed as OR per I unit change in mMRC scale.

Abbreviations: $\mathrm{mMRC}$, modified Medical Research Council; COPD, chronic obstructive pulmonary disease; OR, odds ratio; Cl, confidence interval; $\mathrm{FEV}$, forced expiratory volume in I second.

In contrast to the history of $\mathrm{TB}$, a history of pneumonia was more common in Poland and USA than in Korea. Respiratory infection in childhood has been suggested as a risk factor for COPD, ${ }^{16,17}$ and we did observe higher rates of nonspecific "lung trouble before the age of 16" among COPD cases relative to controls from Korea and Poland. Because COPD subjects are also more susceptible toward developing pneumonia, it is unclear if the high rates of pneumonia in severe COPD subjects in Poland and USA are a cause or consequence (or both) of COPD. Although we excluded subjects known to have diffuse bronchiectasis, COPD with bronchiectasis may be more prevalent among subjects with a previous history of pneumonia; previous reports have suggested that COPD with bronchiectasis may be a more severely symptomatic subgroup within the COPD population. ${ }^{18}$ Further research will be required to determine if the rates of bronchiectasis among severe COPD subjects in Korea are lower than in USA and Poland. The findings of our current study suggest that the differences in the prevalence of respiratory infections, including TB and pneumonia, across countries may contribute to the different clinical features within COPD patients with similar severity of airflow obstruction.

As risk factors for COPD beyond cigarette smoking, we analyzed occupational exposures to dust and noxious gases as risk factors for severe COPD. Occupational exposures to vapors, gases, dust, and fumes have been suggested as risk factors for the development of COPD and increased mortality. ${ }^{19-21}$ Previously, occupational exposures were found to contribute to increased chronic cough and persistent wheeze in the COPDGene study. ${ }^{22}$ In our study, occupational gas and fume exposure was more common in severe COPD subjects from Poland and USA than from Korea. This finding also suggests that different occupational exposures may contribute to different respiratory symptom patterns among countries.

Interestingly, chronic bronchitis and dyspnea were more prevalent among severe COPD subjects in Poland than in Korea or USA. Since chronic bronchitis and dyspnea are symptom-based diagnoses, differential thresholds for reporting symptoms or cultural differences may affect the prevalence of these respiratory symptoms in different countries. As an example, women may respond differently to exposures, and they tend to show severe COPD-related symptoms. ${ }^{23}$ Women comprised a much larger percentage of COPD cases in Poland and USA in our study. Attacks of wheezing and physician-diagnosed asthma were most prominent among COPD cases in Korea. Whether these differences relate to differences in disease pathogenesis or to differences in symptom reporting and health care practices will require further

Table 6 Multivariate models for respiratory illnesses among severe COPD cases in different countries

\begin{tabular}{|c|c|c|c|c|c|c|}
\hline \multirow[t]{2}{*}{ Respiratory illnesses } & \multicolumn{2}{|l|}{ Korea vs Poland* } & \multicolumn{2}{|l|}{ USA vs Poland** } & \multicolumn{2}{|l|}{ USA vs Korea** } \\
\hline & OR with $95 \% \mathrm{Cl}$ & $p$-value & OR with $95 \% \mathrm{Cl}$ & $p$-value & OR with $95 \% \mathrm{Cl}$ & $p$-value \\
\hline Tuberculosis & $3.77(1.77-8.01)$ & 0.0006 & $0.005(<0.00 \mathrm{I}-0.2 \mathrm{I})$ & 0.005 & $0.003(<0.00 \mathrm{I}-0.07)$ & 0.0003 \\
\hline Pneumonia & $0.4 I(0.21-0.80)$ & 0.009 & $1.27(0.81-1.99)$ & 0.3 & $4.97(2.55-9.70)$ & $<0.000 \mathrm{I}$ \\
\hline Physician-diagnosed asthma & 50.8 (I2.3-209.9) & $<0.000 \mathrm{I}$ & $95.6(27.5-332.0)$ & $<0.0001$ & $0.46(0.22-0.95)$ & 0.04 \\
\hline Attacks of bronchitis & $0.06(0.02-0.16)$ & $<0.0001$ & $0.60(0.38-0.96)$ & 0.03 & $16.9(5.5-5 \mid .6)$ & $<0.000$ I \\
\hline Lung trouble before age 16 & $0.7 \mathrm{I}(0.2 \mathrm{I}-2.43)$ & 0.6 & $0.67(0.32-1.42)$ & 0.3 & $4.1(1.1-15.1)$ & 0.03 \\
\hline
\end{tabular}

Notes: *Korean COPD cases are considered the reference population (ie, OR $<1$ denotes "decreased" prevalence in Korean cases). **USA COPD cases are considered the reference population (ie, OR <I denoted "decreased" prevalence in USA cases). Logistic regression models used country of origin as the dependent variable, with independent variables including all five respiratory illnesses as well as age, sex, pack-years of smoking, and post-bronchodilator FEV (\% predicted).

Abbreviations: COPD, chronic obstructive pulmonary disease; OR, odds ratio; $\mathrm{Cl}$, confidence interval; $\mathrm{FEV}_{1}$, forced expiratory volume in I second. 
investigation. Additionally, differences in race, culture, the prevalence of current smokers, and risk factors for respiratory irritation could also influence the different prevalence of respiratory symptoms within COPD patients with similar severity.

Our study has several important limitations, and therefore we view our findings as hypothesis generating results that will require further investigation in other study populations. First, since the enrolled subjects were not selected randomly but were recruited from referral hospitals in each country, it is possible that selection bias could contribute to the observed differences in patients with severe COPD. However, because we focused on severe and very severe COPD patients who would be expected to have already initiated medical attention for their COPD, the impact of selection bias was likely attenuated. The potential impact of differences in subjects' recruitment and treatment with respiratory medications on the observed differences in respiratory symptoms and other respiratory illness will require further investigation. Although the minimum age for enrollment was lower in the USA study (30) than the Poland and Korea studies (40), the youngest participant in the USA study was 39 years old. Second, criteria used to exclude TB patients differed between the TCGS and COPD Exacerbations studies. In TCGS, subjects with significant lung parenchymal destruction related to TB were excluded after reviewing available radiographic studies based on the involvement of more than one lobe, ${ }^{24,25}$ while in the COPD Exacerbations Study, subjects with self-reported chronic lung problems related to TB were excluded. However, it is unlikely that these exclusion criteria account for the large differences in the rates of TB observed between different countries. More systematic evaluation of lung parenchymal damage from prior TB with standardized chest computed tomography scans would be useful in future studies. Third, although we used the same questionnaire items in the three countries, it is possible that regional differences in interpretation of these questions or in the use of medical diagnoses could have influenced our results. It is intriguing that asthma was frequently diagnosed in Korean severe COPD subjects but rarely diagnosed in Polish severe COPD patients; however, it is unclear whether this difference is due to disparate disease characteristics or differences in the use of the diagnostic term of "asthma" in these countries. Fourth, the sample size of the Korean COPD population was smaller than USA and Polish populations, which could have reduced our power to detect differences in the Korean population. Finally, our USA population was enriched for frequent and infrequent COPD exacerbators, rather than including all severe COPD subjects - this may limit generalizability of our results.

In conclusion, this study found that respiratory symptoms of COPD patients and the associated respiratory illnesses were markedly different in severe COPD patients of similar spirometric severity among three countries across continents. Our results suggest that regional, racial, and environmental differences, as well as differences in diagnostic criteria and comorbidities, could be potential contributors to global COPD heterogeneity.

\section{Acknowledgments}

The authors thank Dr Richard A Rosiello and the late Professor Jan Zielinski for their support of the study. This work was supported by NIH grants R01 HL113264, P01 HL114501, and P01 HL105339. The current address of Anne L Fuhlbrigge, Senior Associate Dean for Clinical Affairs, is University of Colorado School of Medicine, Aurora, CO, USA. Dr Fuhlbrigge was part of the Pulmonary and Critical Care Medicine Division of Brigham and Women's Hospital during this study.

\section{Disclosure}

In the past 3 years, Edwin K Silverman received honoraria and consulting fees from Merck, grant support and consulting fees from GlaxoSmithKline, and honoraria and travel support from Novartis. The other authors report no conflicts of interest in this work.

\section{References}

1. Vestbo J, Hurd SS, Agustí AG, et al. Global strategy for the diagnosis, management, and prevention of chronic obstructive pulmonary disease: GOLD executive summary. Am J Respir Crit Care Med. 2013;187: 347-365.

2. Eisner MD, Anthonisen N, Coultas D, et al. An official American Thoracic Society public policy statement: novel risk factors and the global burden of chronic obstructive pulmonary disease. Am J Respir Crit Care Med. 2010;182:693-718.

3. Vaz Fragoso CA, McAvay G, Gill TM, Concato J, Quanjer PH, Van Ness PH. Ethnic differences in respiratory impairment. Thorax. 2014;69:55-62.

4. Buist AS, McBurnie MA, Vollmer WM, et al. International variation in the prevalence of COPD (the BOLD study): a population-based prevalence study. Lancet. 2007;370:741-750.

5. Landis SH, Muellerova H, Mannino DM, et al. Continuing to confront COPD international patient survey: methods, COPD prevalence, and disease burden in 2012-2013. Int J Chron Obstruct Pulmon Dis. 2014; 9:597-611.

6. Hardin M, Zielinski J, Wan ES, et al. CHRNA3/5, IREB2, and ADCY2 are associated with severe chronic obstructive pulmonary disease in Poland. Am J Respir Cell Mol Biol. 2012;47:203-208.

7. Wan ES, DeMeo DL, Hersh CP, et al. Clinical predictors of frequent exacerbations in subjects with severe chronic obstructive pulmonary disease (COPD). Respir Med. 2011;105:588-594.

8. Miller MR, Hankinson J, Brusasco V, et al. Standardisation of spirometry Eur Respir J. 2005;26:319-338. 
9. Ferris B. Epidemiology standardization project (American Thoracic Society). Am Rev Respir Dis. 1978;118:1-120.

10. Silverman EK, Chapman HA, Drazen JM, et al. Genetic epidemiology of severe, early-onset chronic obstructive pulmonary disease. Risk to relatives for airflow obstruction and chronic bronchitis. Am J Respir Crit Care Med. 1998;157:1770-1778.

11. Salvi SS, Barnes PJ. Chronic obstructive pulmonary disease in nonsmokers. Lancet. 2009;374:733-743.

12. Lee C-H, Lee M-C, Lin H-H, et al. Pulmonary tuberculosis and delay in anti-tuberculous treatment are important risk factors for chronic obstructive pulmonary disease. PLoS One. 2012;7:e37978.

13. Willcox PA, Ferguson AD. Chronic obstructive airway disease following treated tuberculosis. Respir Med. 1989;83:195-198.

14. WHO. Tuberculosis country profiles. Available from: http://who.int/ tb/country/data/profiles/en/. Accessed August 24, 2017.

15. Kim JH, Yim JJ. Achievements in and challenges of tuberculosis control in South Korea. Emerg Infect Dis. 2015;21:1913-1920.

16. de Marco R, Accordini S, Marcon A, et al. Risk factors for chronic obstructive pulmonary disease in a European cohort of young adults. Am J Respir Crit Care Med. 2011;183:891-897.

17. Hayden LP, Hobbs BD, Cohen RT, et al. Childhood pneumonia increases risk for chronic obstructive pulmonary disease: the COPDGene study. Respir Res. 2015;16:1-9.

18. Martínez-García M-A, de la Rosa Carrillo D, Soler- Cataluña J-J, et al. Prognostic value of bronchiectasis in patients with moderate-to-severe chronic obstructive pulmonary disease. Am J Respir Crit Care Med. 2013; 187:823-831.
19. Mehta AJ, Miedinger D, Keidel D, et al. Occupational exposure to dusts, gases, and fumes and incidence of chronic obstructive pulmonary disease in the Swiss cohort study on air pollution and lung and heart diseases in adults. Am J Respir Crit Care Med. 2012;185:1292-1300.

20. Darby AC, Waterhouse JC, Stevens V, et al. Chronic obstructive pulmonary disease among residents of an historically industrialised area. Thorax. 2012;67:901-907.

21. Torén K, Järvholm B. Effect of occupational exposure to vapors, gases, dusts, and fumes on COPD mortality risk among Swedish construction workers: a longitudinal cohort study. Chest. 2014;145:992-997.

22. Marchetti N, Garshick E, Kinney GL, et al. Association between occupational exposure and lung function, respiratory symptoms, and high-resolution computed tomography imaging in COPDGene. Am J Respir Crit Care Med. 2014;190:756-762.

23. Kennedy SM, Chambers R, Du W, Dimich-Ward H. Environmental and occupational exposures: do they affect chronic obstructive pulmonary disease differently in women and men? Proc Am Thorac Soc. 2007;4: 692-694.

24. Rhee CK, Yoo KH, Lee JH, et al. Clinical characteristics of patients with tuberculosis-destroyed lung. Int J Tuberc Lung Dis. 2013;17:67-75.

25. Jo YS, Park JH, Lee JK, Heo EY, Chung HS, Kim DK. Risk factors for pulmonary arterial hypertension in patients with tuberculosisdestroyed lungs and their clinical characteristics compared with patients with chronic obstructive pulmonary disease. Int J Chron Obstruct Pulmon Dis. 2017;12:2433-2443. 


\section{Supplementary material}

Table SI Respiratory symptoms, respiratory illnesses, and environmental exposures in only male severe COPD subjects according to country ( $\mathrm{N}[\%]$ or mean \pm standard deviation)

\begin{tabular}{|c|c|c|c|c|}
\hline & $\begin{array}{l}\text { Poland } \\
(n=22 I)\end{array}$ & $\begin{array}{l}\text { Korea } \\
(n=\mid 72)\end{array}$ & $\begin{array}{l}\text { USA } \\
(n=158)\end{array}$ & $p$-value \\
\hline \multicolumn{5}{|l|}{ Respiratory symptoms } \\
\hline Usual cough & $175(79.2)$ & $76(44.2)$ & $76(48.1)$ & $<0.0001$ \\
\hline Usual phlegm & I87 (84.6) & $106(61.6)$ & $99(62.7)$ & $<0.0001$ \\
\hline Chronic bronchitis & $127(57.5)$ & $48(27.9)$ & $67(42.4)$ & $<0.0001$ \\
\hline Wheezing & $175(79.2)$ & $115(66.9)$ & $135(85.4)$ & 0.0002 \\
\hline Attacks of wheezing & $98(44.3)$ & $96(55.8)$ & $67(42.4)$ & 0.03 \\
\hline mMRC dyspnea & $3.3(1.0)$ & $2.5(1.2)$ & $2.6(1.3)$ & $<0.0001$ \\
\hline \multicolumn{5}{|l|}{ Respiratory illnesses } \\
\hline History of pneumonia & $128(57.9)$ & $37(21.5)$ & $103(65.2)$ & $<0.000$ I \\
\hline History of tuberculosis & $24(10.9)$ & $67(39.0)$ & $0(0.0)$ & $<0.0001$ \\
\hline Attacks of bronchitis & $130(58.8)$ & $8(4.7)$ & 71 (44.9) & $<0.0001$ \\
\hline Physician-diagnosed asthma & $3(1.4)$ & $76(44.2)$ & $52(32.9)$ & $<0.000$ I \\
\hline Lung trouble before age 16 & $32(14.5)$ & II (6.4) & $29(18.4)$ & 0.004 \\
\hline \multicolumn{5}{|l|}{ Environmental exposures } \\
\hline Pack-years of smoking & $48.2 \pm 23.6$ & $45.1 \pm 23.6$ & $69.2 \pm 39.4$ & $<0.0001$ \\
\hline Current smoking & $60(27.2)$ & $43(25.0)$ & $31(19.2)$ & 0.2 \\
\hline Age when started smoking & $17.9(3.2)$ & $20.8(5.3)$ & $15.9(4.8)$ & $<0.000$ I \\
\hline Childhood household smoke exposure & $184(83.3)$ & $134(77.9)$ & $128(81.0)$ & 0.4 \\
\hline Occupational dust exposure & $164(74.6)$ & $84(53.9)$ & $104(65.8)$ & 0.0002 \\
\hline Occupational gas/chemical fume exposure & $109(49.6)$ & $20(12.8)$ & $92(58.2)$ & $<0.0001$ \\
\hline
\end{tabular}

Abbreviations: mMRC, modified Medical Research Council; COPD, chronic obstructive pulmonary disease.

\section{Publish your work in this journal}

The International Journal of COPD is an international, peer-reviewed journal of therapeutics and pharmacology focusing on concise rapid reporting of clinical studies and reviews in COPD. Special focus is given to the pathophysiological processes underlying the disease, intervention programs, patient focused education, and self management protocols

\section{Dovepress}

This journal is indexed on PubMed Central, MedLine and CAS. The manuscript management system is completely online and includes a very quick and fair peer-review system, which is all easy to use. Visit http://www.dovepress.com/testimonials.php to read real quotes from published authors. 